\title{
Integrated Approach to e-Commerce Websites Evaluation with the Use of Surveys and Eye Tracking Based Experiments
}

\author{
Paweł Ziemba*, Jarosław Wątróbski ${ }^{\dagger \S}$, Artur Karczmarczyk ${ }^{\dagger}$, Jarosław Jankowski ${ }^{\dagger}$ and Waldemar Wolski ${ }^{\ddagger}$ \\ * Department of Technology, The Jacob of Paradies University \\ ul. Teatralna 25, 66-400 Gorzów Wielkopolski, Poland \\ $\dagger$ West Pomeranian University of Technology in Szczecin \\ ul. Żołnierska 49, 71-210 Szczecin, Poland \\ $\ddagger$ University of Szczecin \\ ul. Mickiewicza 64, 71-101 Szczecin, Poland \\ $\S$ corresponding author
}

\begin{abstract}
Due to high availability of e-commerce website providing similar services and products, the website usability becomes one of the most critical factors affecting online businesses' success. Therefore, website quality and user experience evaluation is an important research task. There are multiple methodologies for performing the evaluation. The proposed in our earlier studies PEQUAL methodology extends the classical eQual method by taking into account different aspects of preference modeling and aggregation derived from Multi-Criteria Decision Analysis (MCDA). This paper extends the PEQUAL methodology further by incorporating eye tracking based measurement and analysis into the criteria set. The results of the conducted empirical verification of proposed approach are presented.
\end{abstract}

\section{INTRODUCTION}

$\mathbf{I}$ N JANUARY 2017 out of the total world population of 7.5 billion people, $50 \%$ were Internet users and $66 \%$ used mobile devices [1]. A growth of 482 million users, i.e. $21 \%$, was observed among active social media users since January 2016. According to January 2016 data [2], 79\% of UK population searched online for a product or service to buy at least once within a 30-days period and $77 \%$ made a purchase. In 2015, the total value of online sales in Europe was 455 billion euro [3], compared to 131.61 billion euro in 2013 and 156.28 billion euro in 2014.

The competition in e-commerce is high. In June 2016 there were 12 million stores online, however only 650 thousands of them $(5.4 \%)$ sold more than $\$ 1,000$ per year [4]. With such hot competition, entrepreneurs try to increase their chances by marketing and using analytic tools [5], refactoring the usability of the website and its assessment [6], providing web content accessibility [7] or ascertaining credibility of the website [8]. The credibility is the perception of being trustworthy and believable and it can be built, among other things, by providing great user experience and high levels of usability and quality [8].

With such a tough competition, it is beneficial to evaluate the websites' quality, usability and user experience [9]. There are multiple website and e-commerce evaluation methods, including eQual[10], SiteQual [11], E-S-QUAL [12] to name just a few. The methods differ in the range of possible applications, assessment scale used, their theoretical basis, verification of solution or minimum number of evaluators.

Since the websites quality evaluation is a multi-criteria problem, the Multi-Criteria Decision Analysis (MCDA) methods can be used to approach it, such as TOPSIS [13] or PROMETHEE [14] in their classic or fuzzy variants [15] [16]. Also a hybrid approach is possible that combines the classic methods with MCDA methods, such as PEQUAL [17].

The aforementioned methods are commonly based on survey data, which causes some problems. The number of questions needs to be limited so the survey is manageable for the respondents. Also real users from the target group should be involved in response collecting process [10]. On the other hand, a growing popularity of research tools based on eye tracking can be observed. Originally they were used mainly in medicine, however, currently we can also find studies on user experience [18], website quality [19] and usability evaluation [20] founded on the data collected with these tools [21].

While numerous studies based on eye tracking and survey website evaluation can be found, the lack of integrated eye tracking and MCDA approach is observed. Therefore, the combination of the eye tracking tools' results and the MCDA methods foundations constitue an interesting research gap, which this paper is addressing. The main objective of this paper is to extend the PEQUAL website quality evaluation model of the world most popular e-commerce websites by combining the EQUAL criteria survey data with the perceptual measurements criteria. An eye-tracking device has been used to collect selected metrics and they have been included into the PEQUAL method.

The paper is split into sections. Section II contains literature review. The methodological framework of the proposed approach is presented in section III. Section IV contains 
empirical study results. The conclusions and future directions are outlined in section $\mathrm{V}$.

\section{LITERATURE REVIEW}

\section{A. Website Quality, Usability and User Experience}

It has been noted in [32] and [33] that the focus time span of the average human is eight seconds. Therefore, the websites' designers must create the websites in a manner that the user will be able to find all sought data easily within this time. In other terms, the website needs to be characterized by high levels of quality, usability and user experience.

As noted in [34], the quality and usability are terms related to each other. The ISO 9241-11:1998 standard [35] defines usability as the "extent to which a product can be used by specified users to achieve specified goals with effectiveness, efficiency and satisfaction in a specified context of use", and the ISO 25010:2011 standard [36] defines it as "the ability of software to be in intelligible, easy to learn and use as well as attractive to the user in specified circumstances".

The authors of [9] point out that it is beneficial to evaluate the quality, usability and user experience of a website. It is especially important, considered the systems' usability changes over time, depending among other things on the user preferences or software and hardware evolution [34].

The authors of [37] grouped the usability evaluation methods into five groups: user testing, inspection methods, inquiry methods, analytical modeling and simulation methods. The website quality evaluation methods, on the other hand, can be split into three groups [38]: expert evaluation, user traces analysis, interviews and surveys.

\section{B. Classic Website Evaluation Methods}

The methods employed in websites evaluation differ in the type, quantity and structure of criteria used. However, they often follow the same procedure, where initially the users' thoughts are obtained by surveys or questionnaires, and later the responses are put on a Likert scale. The actual degree of the scale depends on the method.

The Ahn method utilizes the Technology Acceptance Model (TAM) provided by Davis [39]. It can be used for evaluation of e-banking and e-commerce. It utilizes 54 criteria with assessment scale of 1-7. Consistency reliability of the questionnaires is performed [40]. The SiteQual method [41] is based on the set of 28 criteria, each assessed in the scale of 1-9. It utilizes the SERVQUAL service quality instrument [42] and information quality criteria to allow B2C websites quality evaluation [11]. The E-S-QUAL [12] and E-RecS-Qual methods evolved from the SERVQUAL technique and can be utilized for the evaluation of e-banking and e-commerce. They are based on two sets of 22 and 11 criteria assessed in the scale of 1-5 [43]. The Website Attribute Evaluation System (WAES) method [44] is intended for surveying office and organization sites. It is an expert evaluation method of examining the website quality. The Website Evaluation Questionnaire (WEQ) [45] is a research-tool developed for informational websites evaluation. It uses 18 criteria and additional 8 negative criteria for verification. Web Portal Site Quality (WPSQ) method [46] provides means to evaluate information portals, and the obtained solution is then verified by a set of complex reliability tests. The Website Quality Model (WQM) method [47] uses the Kano quality model, in which there are three levels of clients' desires: essential, execution and energizing.

Last, but not least, one of the most popular websites evaluation methods is the eQual method [10]. It has been successfully used for the evaluation of e-commerce, e-government, university websites and WAP websites. It uses 22 criteria divided into Usability, Information Quality and Service Interaction quality groups. The Usability group is further divided into Usability and Design subcategories, and the Service Interaction quality group is further divided into Trust and Empathy subcategories.

\section{Eye Tracking Devices in Website Evaluation}

As it was pointed out, the original area of the eye tracking (ET) usage has been significantly expanded with new research areas. The usability testing and user experience (UX) is one of the current, dynamically developing environments. UX is a concept related to usability and it is defined as "a momentary, primarily evaluative feeling (good-bad) while interacting with a product or service" [48]. Literature review provides a broad overview of the use of ET in these fields. In categorizing this area, two groups of the eye tracking applications can be identified in the usability research:

- ET based usability studies,

- ET + surveys based approaches.

The fundamental difference between these groups is that group II includes usability evaluation surveys either before or after the ET study, and in the case of group I, the usability assessment is based only on measurable factors, such as AOI [18], TFF, FBT [22], visits and revisits [19] or the time required to complete a given task [31]. The cited works describe the indicated measures in detail.

When analyzing the first group (see Table I), it can be observed that in many works, even the ET perceptual measurements alone are indicated as an effective tool of website evaluation. It is worth pointing out that the practical areas of the research cover various practical areas of commercial websites, such as e-commerce [18], social commerce [23], online booking [30] or tourism [24]. The principal limitation of these studies is, however, a relatively narrow focus of each of them on the selected measurement aspects, e.g. in [23] the impact of the price level, position and the presentation of the product by a famous person on the fixation time on the website and on the price is analyzed, while in [22] location typicality and efficiency in finding target web objects on the homepages was analyzed.

In the case of the second group, ET + surveys based approaches (see Table II), the vast majority of the analyzed works is oriented towards a wider usability or UX of the analyzed web pages. Thus, the introduction of the survey data into the final assessment extends the scope of the evaluation process. 
TABLE I

EYE TRACKING USAGE IN WEBSITES EVALUATION

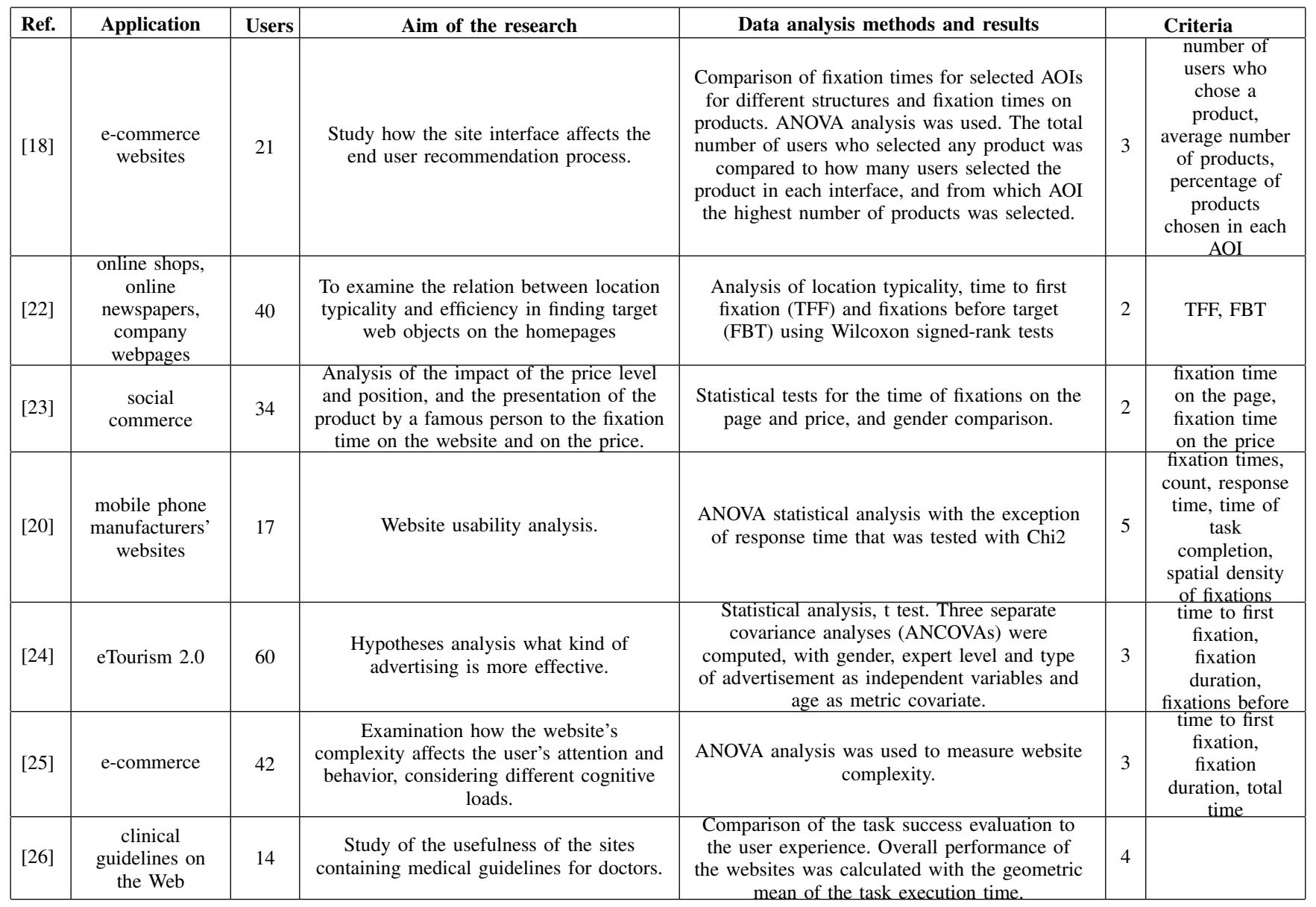

Additionally, it should be noted that the surveys evaluations in the second group are often based on the methodological patterns from the AHN or eQual group of methods (see subsection II-B). These works have, contrarily to the ones from the first group, a broad domain scope and include the assessment of usability in the e-commerce [27], online banking [28], e-government [29] or online booking systems [30].

When analyzing the methodological aspects of the works contained in Table I and II, one should note the dominant role of the research with strong sociological rigor (oriented on the verification of the selected statistical hypotheses), and as a consequence, their methodological side is based on the statistical analysis elements, such as statistical tests or ANOVA analyzes. However, the statistical analysis techniques (correlation [27], covariance of variables [24] or ANOVA [25]) remain the basic research tool. Also in the case of the second group, the sociological cognitive tone of research remains dominant.

\section{MCDA Website Evaluation Methods}

Apart from the evaluation methods mentioned above, during the literature review, endeavors at utilizing the MCDA tech- niques for websites' assessment can be found. The MCDA approach is justified, since the evaluation of websites is a multi-criteria problem, in which multiple dimensions and measurements need to be considered [49]. For example, Chmielarz broadly utilizes scoring method to assess an extensive variety of business oriented websites [50], [51], [52]. Lee and Kozar applied the AHP method to evaluate e-tourist and e-commerce websites [53]. Sun and Lin used the fuzzy TOPSIS method to evaluate e-commerce websites [15]. Del Vasto-Terrientes et al. used the ELECTRE-III-H method on traveler websites [54]. Furthermore, hybrids of different MCDA techniques can be used [16], [55], [56].

The literature review demonstrates that the majority of the MCDA use surveys to collect data for the evaluations. The weights of the criteria are commonly compared pairwise and AHP technique is used. While most of the methods use a predetermined set of criteria, some papers used theoretical bases identifying the need for presenting both specific quality measures and criteria [54], [55].

The application of the MCDA methods to the websites' evaluation problems has a greater potential than just constructing a ranking. This can be illustrated by a model of a decision 
TABLE II

EYE TRACKING COMBINED WITH SURVEYS USAGE IN WEBSITES EVALUATION

\begin{tabular}{|c|c|c|c|c|c|c|}
\hline Ref. & Application & Users & Aim of the research & Data analysis methods and results & & Criteria \\
\hline [27] & $\begin{array}{l}\text { e-commerce, } \\
\text { B2B }\end{array}$ & 25 & $\begin{array}{l}\text { Study of the difference in perception of } \\
\text { B2B sites by different cultural groups. }\end{array}$ & $\begin{array}{c}\text { Calculation of the correlation, to what extend } \\
\text { each of the } 7 \text { criteria affect the attractiveness } \\
\text { of the pages and comparison of two cultural } \\
\text { groups. }\end{array}$ & 7 & \\
\hline$[28]$ & online banking & 10 & $\begin{array}{l}\text { Usability study of the electronic banking } \\
\text { login interface. }\end{array}$ & $\begin{array}{c}\text { The results consisted of comparison of the } \\
\text { numerical data (criteria) obtained during the } \\
\text { study and heat maps and AOI trajectory maps. } \\
\text { Data obtained during the interview was } \\
\text { analyzed. }\end{array}$ & 3 & $\begin{array}{l}\text { time to first } \\
\text { fixation, } \\
\text { fixation } \\
\text { duration, total } \\
\text { time }\end{array}$ \\
\hline [19] & e-commerce & 38 & $\begin{array}{l}\text { Study of the impact of the presence of a } \\
\text { human brand element on the quality of } \\
\text { online shopping decisions }\end{array}$ & ANOVA statistical analysis. & 4 & $\begin{array}{l}\text { viewers, first } \\
\text { view, watched } \\
\text { time, revisits }\end{array}$ \\
\hline [9] & $\begin{array}{l}\text { websites of } \\
\text { mobile service } \\
\text { providers } \\
\text { (telecoms) }\end{array}$ & 44 & $\begin{array}{l}\text { Comparative evaluation of user experience } \\
\text { (UX) and usability. }\end{array}$ & $\begin{array}{l}\text { Basic statistics. Comparison of the obtained } \\
\text { results of each criterion for each page (min, } \\
\text { max mean, median). For each value: job } \\
\text { completion time, time and count of fixations } \\
\text { since first click, time to find the target, number } \\
\text { of pages viewed during task execution. }\end{array}$ & 3 & \\
\hline [29] & $\begin{array}{l}\text { e-government } \\
\text { websites }\end{array}$ & 9 & $\begin{array}{c}\text { Study of usefulness of e-government } \\
\text { websites. }\end{array}$ & $\begin{array}{c}\text { Basic statistics of the experiment and } \\
\text { comparison of the results from the eye tracker } \\
\text { with the results from the survey after the } \\
\text { experiment. }\end{array}$ & 3 & $\begin{array}{l}\text { task completion } \\
\text { time, fixation } \\
\text { duration, } \\
\text { fixations count }\end{array}$ \\
\hline$[30]$ & $\begin{array}{l}\text { online hotel } \\
\text { booking } \\
\text { websites }\end{array}$ & $\begin{array}{c}16 \\
\text { valid }\end{array}$ & $\begin{array}{l}\text { The purpose of the study was to analyze } \\
\text { the impact of images and the size of } \\
\text { selection sets on the decision-making } \\
\text { process of hotel reservations online. }\end{array}$ & $\begin{array}{l}\text { Based on the data collected in a combined } \\
\text { (eye tracking and surveys) experiment, } \\
\text { hypotheses were statistically confirmed by } \\
\text { comparing the time and number of fixations. }\end{array}$ & 3 & $\begin{array}{l}\text { task completion } \\
\text { time, fixation } \\
\text { duration, } \\
\text { fixations count }\end{array}$ \\
\hline [31] & $\begin{array}{l}\text { e-commerce, } \\
\text { Amazon }\end{array}$ & 30 & $\begin{array}{l}\text { The purpose of this study was to examine } \\
\text { the credibility of the seller and to find the } \\
\text { factors that influence the choice of } \\
\text { payment methods for online purchases. }\end{array}$ & $\begin{array}{l}\text { Confirmation or denial of hypotheses using } \\
\text { statistics on the choice of payment method, } \\
\text { with each criterion. Data analysis methods: - } \\
\text { ANOVA for price and sales criteria in the } \\
\text { choice of payment method. - Fixation times in } \\
\text { AOI (price, sales) in different product types. - } \\
\text { Logistic regression to identify factors } \\
\text { influencing the choice of payment method. }\end{array}$ & 2 & $\begin{array}{l}\text { task completion } \\
\text { time, fixation } \\
\text { duration }\end{array}$ \\
\hline
\end{tabular}

process defined by Guitouni [57], where exploitation and recommendation stages are important steps. On the operation stage, the analysis of the obtained solution can be performed, such as its stability examination [58], [59] or the analysis of the decision-makers' preference.

As demonstrated in [17] and [43], MCDA is an effective multi-aspect data analysis tool. However, in order to use the MCDA methodology properly, the decision support / evaluation model needs to be supplied with the complete domain data set [60], [61], [57]. The aforementioned MCDA requirements, along with the advantages of ET and ET + surveys approaches, motivate the authors' contribution to modify the approach presented in [17] and [43] and to introduce to the evaluation model the ET-based data.

\section{Methodological Framework}

\section{A. PEQUAL Methodological Foundations}

The website evaluation procedure presented in this paper is based on the PEQUAL methodology of website quality assessment [17]. The methodology depends on the eQual and PROMETHEE II methods. The eQual method has its foundations in Quality Function Deployment. The PROMETHEE II method is a popular MCDA method that employs pairwise comparison and outranking flows to produce a ranking of best decision variants [43].
Initially, pairwise comparison of the alternatives on particular criterion is considered. The preference of one alternative over another on a criterion $j$ can be expressed with the usage of a preference function $P_{j}(a, b)$, where $a$ and $b$ belong to the $A$ set of alternatives. For each $a$ and $b$ :

$$
0 \leq P_{j}(a, b) \leq 1
$$

Promethee methods offer six preference functions: usual criterion, U-shape criterion, V-shape criterion, level criterion, v-shape with indifference criterion, Gaussian criterion [14]. Next, aggregated preference index of alternatives is calculated with formula (2).

$$
\left\{\begin{array}{l}
\pi(a, b)=\sum_{j=1}^{k} P_{j}(a, b) w_{j} \\
\pi(b, a)=\sum_{j=1}^{k} P_{j}(b, a) w_{j}
\end{array}\right.
$$

where $w_{j}$ is the weight assigned to the $j$-th criterion. $\pi(a, b) \sim 0$ implies a weak and $\pi(a, b) \sim 1$ implies a strong global preference of $a$ over $b$.

$P_{j}(a, b), P_{j}(b, a), \pi(a, b)$ and $\pi(b, a)$ are real numbers without units, completely independent of the scales of the criteria.

Subsequently, the obtained indices are used to calculate positive and negative outranking flows with formulae (3) and (4) $[14]:$ 


$$
\begin{aligned}
\phi^{+}(a) & =\frac{1}{n-1} \sum_{x \in A} \pi(a, x) \\
\phi^{-}(a) & =\frac{1}{n-1} \sum_{x \in A} \pi(x, a)
\end{aligned}
$$

The $\phi^{+}(a)$ value represents how an alternative a is outranking other alternatives, whereas the $\phi^{-}(a)$ value shows how the alternative is outranked by the others.

Eventually, the net outranking flow is calculated as a difference between the positive and negative outranking flows:

$$
\phi(a)=\phi^{+}(a)-\phi^{-}(a)
$$

In the Promethee I method, two rankings are produced, based separately on the $\phi^{+}(a)$ and $\phi^{-}(a)$ values. In the Promethee II method, a single ranking is created, based exclusively on the $\phi(a)$ value.

\section{B. Modified PEQUAL Framework Gaze Data Analysis}

To perform the empirical research, at first, the survey results from [17] were combined with the data from a perceptual evaluation study. The original PEQUAL result set contained data collected from surveys from 41 users, who were experienced in online shopping.

The experiment result set was obtained from a group of 20 students, using an eye tracking device and GazePoint software. The same set of 10 websites as in [17] was studied: Alibaba, Amazon, Apple, BestBuy, eBay, Macy's, Rakuten, Staples, Target and Walmart. Three slides were prepared for each of the websites:

- home page - the front page of each website, containing, among other things, a product search form and a list of categories;

- product page - the main page of a single product in offer, containing a description, images and price;

- payment page - one of the last steps of the purchase transaction, the page containing the payment method choice.

Each slide from the total set of 30 slides was displayed to the participants for a period of 10 seconds, with a 3 seconds pause between slides. An area of interest (AOI) was configured on each of the slides. On the ones presenting home pages, the participants were given the task to locate a piece of electronic - either smartphone or a watch. On the product page slides, the students were supposed to locate the price. Finally, on the payment page slides, they were asked to locate the "PayPal" payment method.

During the experiment, the software collected the following data:

- E1 - viewers - number of people who have visited the configured areas of interest (AOI);

- E2 - first view [s] - time elapsed in seconds before the area was noticed for the first time;

- E3 - watched time [s] - time spent on a given AOI, expressed in seconds;

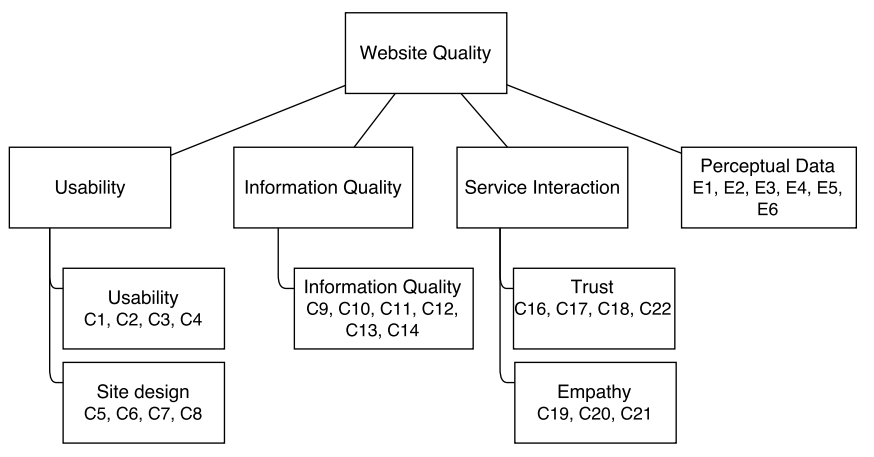

Fig. 1. Combined criteria hierarchy

- E4 - watched time [\%] - time spent on a given AOI, expressed in percent;

- E5 - revisitors - the number of participants who returned to the AOI;

- E6 - revisits - number of revisits to the AOI.

Eventually, the obtained criteria E1-E6 were combined with the PEQUAL criteria C1-C22. The resulting criteria hierarchy is presented on Figure 1.

The results of the questionnaires from [17] and the empirical data from the experiment were used to build a performance table. Three scenarios were taken into consideration for the perceptual data. In the first scenario, the data regarding the home pages of the websites was used. In the second one, the data from the product pages was utilized. Finally, in the third scenario, the data from the payment pages was used.

The data in each of the scenarios was later aggregated using the Promethee II method and rankings were generated. In the next step, a broad graphical analysis of the received rankings was carried out with the usage of GAIA plane. In the third step, Promethee II and GAIA analysis was performed on the survey data combined with the averaged perceptual data. In the fourth step, sensitivity analysis was performed and stability of the obtained ranking was verified. In the next step, uncertainty analysis was performed. Finally, a comparison of the obtained ranking to a ranking based on the Gaussian preference function was performed. The results were compared to the ones received in the original PEQUAL method [17] on each step of the procedure. The presented approach is depicted in Figure 2.

\section{RESULTS}

\section{A. Promethee II Based Analysis}

In the first step of the research, the averaged values from [17] were used along with the perceptual data to build a performance table for the Promethee II method. For the C1$\mathrm{C} 22$ criteria, the $\mathrm{V}$-shape preference function was used, with the indifference threshold $\mathrm{q}=0$ and the preference threshold $\mathrm{p}=7$ (maximum value in the 7-degree Likert scale used in the study), to ascertain comparability of the results received.

For the E1-E6 criteria, the V-shape preference function with indifference threshold $\mathrm{q}=0$ was used as well, however, since 


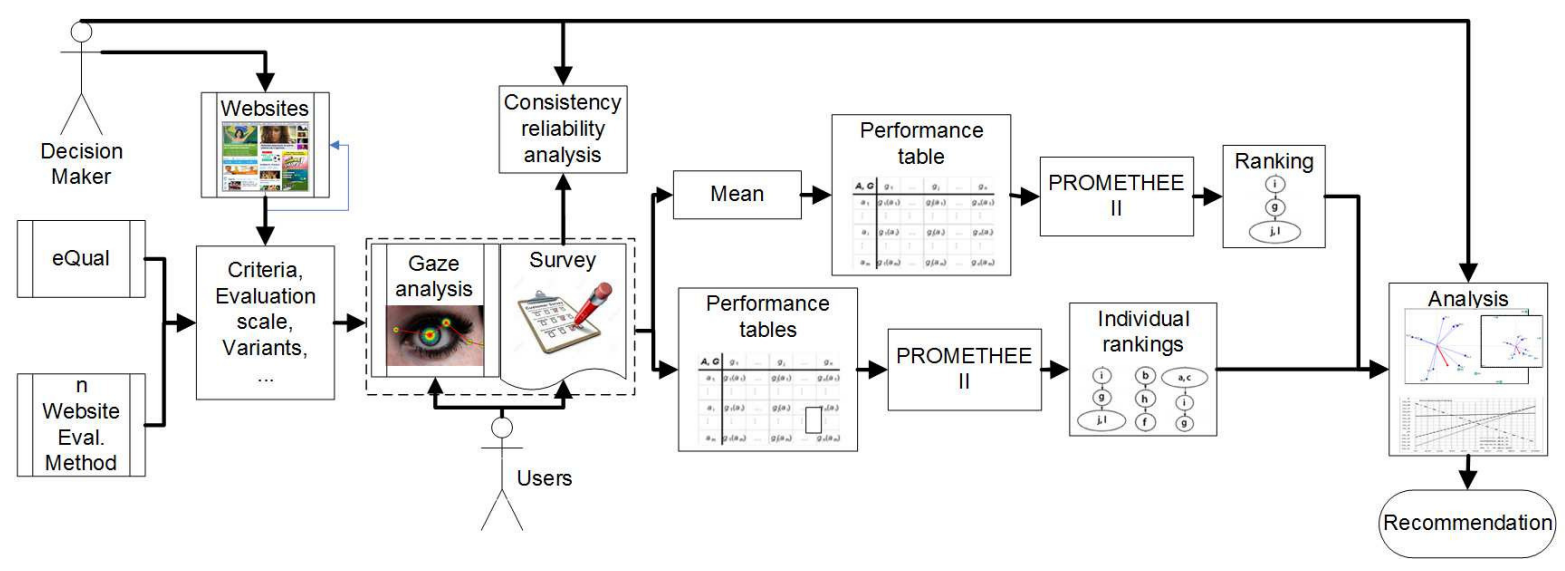

Fig. 2. Website evaluation process using PEQUAL methodology combined with perceptual evaluation criteria.

the perceptual data received is expressed in various units and scales, the preference threshold $\mathrm{p}$ was set for the criteria E1, $\mathrm{E} 3, \mathrm{E} 4$ and $\mathrm{E} 5$ to the maximum possible value, for the criterion E2 it was set to 5 seconds (a half of the slide display time), and for the criterion E6 it was set to 10 revisits. The preference direction for all criteria but E2 was maximized.

The weights were assigned to the criteria in a manner that the C1-C22 set of eQual survey based criteria total weight was $50 \%$ and the E1-E6 set of gaze based criteria total weight was $50 \%$. The weights within the $\mathrm{C} 1-\mathrm{C} 22$ criteria set and within the E1-E6 criteria set were distributed equally, $2.27 \%$ for each $\mathrm{C}$ criterion and $8.34 \%$ for each $\mathrm{E}$ criterion. The weights distribution is presented in Table III.

For the reasons of brevity, the performance tables for scenarios 1-3 were merged into a single table. The Promethee II method was applied on each of the scenarios and the resulting rankings are presented in Table IV. The results originally obtained in [17] are presented for reference in Table V.

It can be observed that the introduction of perceptual measurements data into the analysis modified the ranking of the websites. However, the three best websites from [17] analysis, i.e. Apple, Amazon, eBay, are still in the group of the first five best websites in the combined criteria rankings. Surprisingly, the Alibaba website has dropped significantly in the new rankings, from the fourth rank to the last four ranks in the new rankings. It is visible, that the ranking varies depending on the page studied in the perceptual research. The differences might be caused by the fact that in the original study, the surveys collected opinions about the website in general. The perceptual evaluation, on the other hand, was performed on three specific pages of the website. This information can be used to find areas requiring improvement in the websites analyzed. For example, when product or payment pages are considered, Amazon receives the first rank. However, in the scenario where the users where asked to locate a piece of electronic on the home page, Amazon ranks much worse, with 5th position in the ranking. This might mean that the layout of the home page of this website does not expose electronic devices enough.
TABLE III

WEIGHTS ASSIGNED TO CRITERIA, GROUPS AND CLUSTERS.

\begin{tabular}{|c|c|c|c|}
\hline Cluster of criteria & Group of criteria & Criterion & Weight \\
\hline \multirow{8}{*}{$\begin{array}{c}\text { Usability } \\
18.2 \%\end{array}$} & \multirow{4}{*}{$\begin{array}{c}\text { Usability } \\
9.1 \%\end{array}$} & $\mathrm{C} 1$ & $2.27 \%$ \\
\hline & & $\mathrm{C} 2$ & $2.27 \%$ \\
\hline & & $\mathrm{C} 3$ & $2.27 \%$ \\
\hline & & $\mathrm{C} 4$ & $2.27 \%$ \\
\hline & \multirow{4}{*}{$\begin{array}{c}\text { Site design } \\
9.1 \%\end{array}$} & $\mathrm{C} 5$ & $2.27 \%$ \\
\hline & & C6 & $2.27 \%$ \\
\hline & & $\mathrm{C} 7$ & $2.27 \%$ \\
\hline & & $\mathrm{C} 8$ & $2.27 \%$ \\
\hline \multirow{7}{*}{$\begin{array}{c}\text { Information } \\
\text { quality } \\
15.9 \%\end{array}$} & \multirow{7}{*}{$\begin{array}{c}\text { Information } \\
\text { quality } \\
15.9 \%\end{array}$} & C9 & $2.27 \%$ \\
\hline & & $\mathrm{C} 10$ & $2.27 \%$ \\
\hline & & $\mathrm{C} 11$ & $2.27 \%$ \\
\hline & & $\mathrm{C} 12$ & $2.27 \%$ \\
\hline & & $\mathrm{C} 13$ & $2.27 \%$ \\
\hline & & $\mathrm{C} 14$ & $2.27 \%$ \\
\hline & & $\mathrm{C} 15$ & $2.27 \%$ \\
\hline \multirow{7}{*}{$\begin{array}{c}\text { Service } \\
\text { Interaction } \\
15.9 \%\end{array}$} & \multirow{4}{*}{$\begin{array}{l}\text { Trust } \\
9.1 \%\end{array}$} & $\mathrm{C} 16$ & $2.27 \%$ \\
\hline & & $\mathrm{C} 17$ & $2.27 \%$ \\
\hline & & $\mathrm{C} 18$ & $2.27 \%$ \\
\hline & & $\mathrm{C} 22$ & $2.27 \%$ \\
\hline & \multirow{3}{*}{$\begin{array}{c}\text { Empathy } \\
6.8 \%\end{array}$} & $\mathrm{C} 19$ & $2.27 \%$ \\
\hline & & $\mathrm{C} 20$ & $2.27 \%$ \\
\hline & & $\mathrm{C} 21$ & $2.27 \%$ \\
\hline \multirow{6}{*}{$\begin{array}{l}\text { Perceptual } \\
50 \%\end{array}$} & \multirow{6}{*}{$\begin{array}{l}\text { Perceptual } \\
50 \%\end{array}$} & E1 & $8.34 \%$ \\
\hline & & E2 & $8.34 \%$ \\
\hline & & E3 & $8.34 \%$ \\
\hline & & E4 & $8.34 \%$ \\
\hline & & E5 & $8.34 \%$ \\
\hline & & E6 & $8.34 \%$ \\
\hline
\end{tabular}

\section{B. Graphical Analysis of Promethee II Solution}

The results obtained by the Promethee II method were additionally analyzed using the GAIA planes. Figures 3a-i depict the scores of this analysis separately for individual criteria, groups and clusters for each of the three analyzed criteria. 
TABLE IV

RANKING OF WEBsites BASED on PROMETHEE II AND A) HOME PAGES, B) PROduCt PAGES, C) PAyMENT PAGES, D) AVERAGE PERCEPTUAL EVALUATION DATA (V-SHAPE PREFERENCE FUNCTION)

\begin{tabular}{|l|c|c|c|c|c|c|c|c|c|c|c|}
\hline & Website & Alibaba & Amazon & Apple & BestBuy & eBay & Macy's & Rakuten & Staples & Target & Walmart \\
\hline \multirow{2}{*}{$\mathbf{a}$} & $\phi$ & -0.0899 & 0.0266 & 0.0547 & 0.0805 & 0.055 & -0.063 & -0.0324 & -0.0157 & 0.0369 & -0.0528 \\
\cline { 2 - 14 } & Rank & 10 & 5 & 3 & 1 & 2 & 9 & 7 & 6 & 4 & 8 \\
\hline \multirow{2}{*}{ b } & $\phi$ & -0.0369 & 0.0565 & 0.032 & 0.0032 & 0.0371 & 0.0123 & -0.0205 & 0.0094 & -0.0331 & -0.06 \\
\cline { 2 - 13 } & Rank & 9 & 1 & 3 & 6 & 2 & 4 & 7 & 5 & 8 & 10 \\
\hline \multirow{2}{*}{ c } & $\phi$ & -0.0364 & 0.1136 & 0.0782 & -0.016 & 0.0708 & -0.0616 & -0.095 & 0.0739 & -0.1042 & -0.0232 \\
\cline { 2 - 13 } & Rank & 7 & 1 & 2 & 5 & 4 & 8 & 9 & 3 & 10 & 6 \\
\hline \multirow{2}{*}{ d } & $\phi$ & -0.0543 & 0.0656 & 0.055 & 0.0227 & 0.0543 & -0.0373 & -0.0491 & 0.0222 & -0.0335 & -0.0456 \\
\cline { 2 - 12 } & Rank & 10 & 1 & 2 & 4 & 3 & 7 & 9 & 5 & 6 & 8 \\
\hline
\end{tabular}

TABLE V

RANKING OF WEBSITES BASED ON PROMETHEE II AND AVERAGE CRITERIA EVALUATIONS AS IN [17]

\begin{tabular}{|c|c|c|c|c|c|c|c|c|c|c|}
\hline Website & Apple & Amazon & eBay & Alibaba & Walmart & Macy's & BestBuy & Staples & Rakuten & Target \\
\hline$\phi$ & 0.1037 & 0.0822 & 0.0629 & -0.0137 & -0.0191 & -0.0272 & -0.0343 & -0.0380 & -0.0559 & -0.0607 \\
\hline Rank & 1 & 2 & 3 & 4 & 5 & 6 & 7 & 8 & 9 & 10 \\
\hline
\end{tabular}

The analysis of Figure $3 \mathrm{a}$ shows that the criteria support the five leading variants from ranking in Table IVa, i.e. BestBuy, eBay, Apple, Target and Amazon, in varying degrees. BestBuy, eBay and Target are supported by the perceptual criteria, while Amazon and Apple are supported by the survey criteria. The criteria E1, E5 and E2 have the highest impact on the final ranking. No conflicts are observed between the perceptual criteria, however, they are in strong conflict with the criterion $\mathrm{C} 11$, which means that the websites which are highly evaluated with regard to this criterion receive lower evaluation in perceptual study. Because of the length of the $\mathrm{C} 11$ criterion vector, the E3, E4 and E6 criteria would be affected mostly. The interpretation of this fact can be that the websites providing timely information, at the same time introduce some distraction which reduces the length of watching and the number of revisits in the AOI.

The analysis of Figure $3 \mathrm{~d}$ demonstrates that most of the criteria, survey and perceptual alike, support the three leading websites from ranking in Table IVb. It can be observed, that the vectors of the criteria E5 and E6, as well as of the criteria E3 and E4, are pointing in very similar directions. This means that receiving higher score in E5 criterion resulted in getting higher score in E6 criterion, and similarly scoring higher in E3 resulted in better result in E4. The C5 criterion (attractive appearance of the website) is pointing in similar direction as the E1 criterion, which might mean that when the website look was more appealing, the attention of more users was attracted to the AOI. However, the rest of the perceptual criteria are in conflict with the criterion $\mathrm{C} 5$, which could mean, that the attractive appearance of the website resulted in smaller number of revisits, shorter watch time, as well as longer time to notice the AOI.

When analyzing the Figure $3 \mathrm{~g}$, one can find out that almost all criteria support the four leading websites from the ranking in Table IVc. It is confirmed by the $\phi$ net outranking flow values. The four leading websites have positive $\phi$ values, whereas the remaining six websites have negative $\phi$ values, which means the latter are more outranked by all the criteria.

Subsequently, an analysis of GAIA planes with groups (Figures 3b, 3e, 3h) and clusters (Figures 3c, 3f, 3i) of criteria was performed. All the six figures demonstrate that the perceptual criteria are represented on the GAIA planes by axes more-or-less orthogonal to the Service Interaction and Usability survey criteria clusters, which means that these criteria clusters are not related to each others in terms of preferences.

Figures 3b, 3c, 3e, 3f show that the Information Quality axis is less orthogonal to the Perceptual axis than the rest of the groups and clusters on the home pages and the product pages, which means that these clusters are expressing slightly similar preferences. However, figures $3 \mathrm{~h}$ and $3 \mathrm{i}$ show that on the payment pages the Information Quality axis is orthogonal to the Perceptual axis, meaning they are unrelated to each other in terms of preferences. On the payment pages it is the Service Interaction cluster, and, more precisely, the Trust group, that expresses the greatest preferences' similarity to the Perceptual cluster.

\section{Promethee II and GAIA Analysis Based on Averaged Perceptual Data}

In the next step, the perceptual data from the 3 scenarios was averaged and only then was it combined with the survey data. Subsequently, Promethee II analysis was performed on the received data set. The ranking produced by this analysis is presented in Table IVd. It differs from the rankings calculated with the data from the separate home, product and payment page perceptual evaluations, however Amazon, Apple and eBay websites remain the leaders. It is worth noting, that in the ranking based on the averaged perceptual data, these three websites receive positions most similar to the ranks received in the original PEQUAL ranking (Table V). 

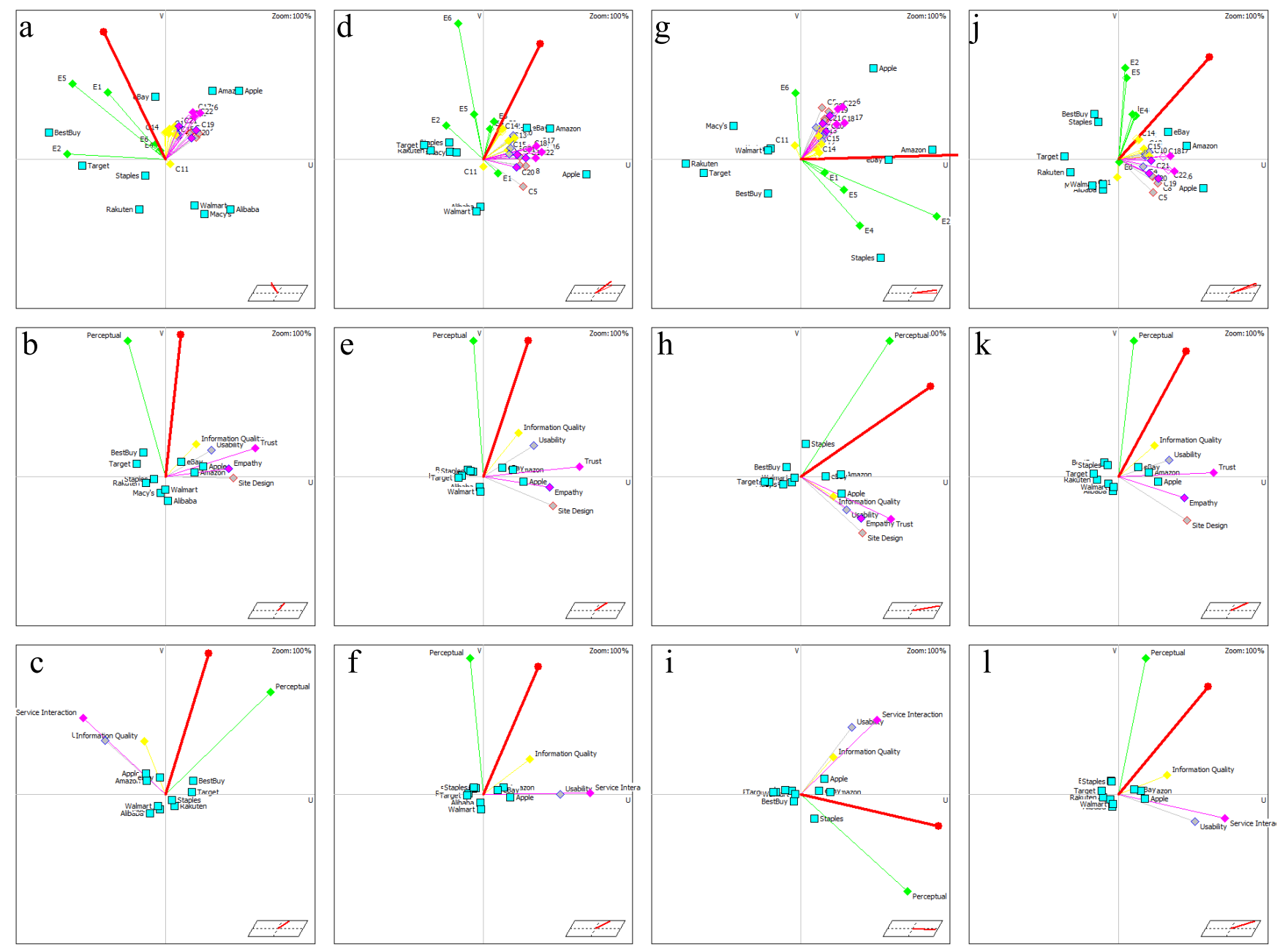

Fig. 3. GAIA analysis for home page scenario: a) criteria, b) groups, c) clusters; product page scenario d) criteria, e) groups, f) clusters; payment page scenario: g) criteria, h) groups, i) clusters; averaged data scenario: j) criteria, k) groups, l) clusters;

GAIA planes analysis was also performed for the new combined data set. Figures $3 \mathrm{j}-1$ depict the GAIA planes criteria, groups and criteria respectively. Figure $3 \mathrm{j}$ shows that the three leading websites are supported in various degrees by almost all criteria, both perceptual and survey. The websites with rank 4 and 5, i.e. BestBuy and Staples, are supported by the perceptual criteria, which explains why they advanced from ranks 7 and 8 in the ranking based on the survey data exclusively.

The analysis of the clusters in Figure 31 shows that when the averaged perceptual data from the three scenarios is used, the Service Interaction cluster is not related to the Perceptual cluster in the terms of preferences, and the Information Quality cluster expresses slightly similar preferences to the Perceptual cluster. A very small conflict can be noticed between the Usability and Perceptual clusters' preferences. The analysis of Figure 3k allows to observe that it is the Site Design group of the Usability cluster that is conflicted with the Perceptual cluster, whereas the Usability group is expressing slightly similar preferences to the Perceptual cluster.

\section{Sensitivity Analysis}

Apart from GAIA analysis, sensitivity analysis of the rankings, taking into account changes in weights of criteria, was performed. Table VI presents the ranges of stability for the weights of the criteria clusters.

It can be observed, that the stability of the ranking depends on the perceptual data scenario chosen. The ranking based on the payment page scenario appears to be the most stable one, and the home page scenario ranking seems to be the least stable one. It is important to notice, that the weight of the Perceptual cluster criteria cannot be reduced below some determined value.

When the results of the stability analysis are compared to the PEQUAL's one, it can be observed that the rankings based on the combined criteria are more sensitive to the weights' changes. This might be caused by the fact that only 6 perceptual criteria were added, so a change in the weight of 
each of them results in more significant changes than in the case of the original 22 PEQUAL criteria.

\section{E. Uncertainty Analysis}

In the subsequent step of the analysis, the influence of the uncertainty of the partial evaluations on the sequence of the rankings was verified. The preference function was modified to $\mathrm{V}$-shape with indifference area, where the preference threshold $\mathrm{p}$ remained unchanged and the indifference threshold was set to $\mathrm{q}=1$ for the $\mathrm{C} 1-\mathrm{C} 22$ criteria, to remain comparable with the PEQUAL analysis in [17], and to $q=10$ for $E 1, q=9$ for $E 2$, $\mathrm{q}=1$ for $\mathrm{E} 3, \mathrm{q}=10$ for $\mathrm{E} 4, \mathrm{q}=10$ for $\mathrm{E} 5$ and $\mathrm{q}=1$ for E6. The obtained ranking is presented in Table VII.

There was a shift in the ranking between Amazon and Apple, also Staples received a higher rank of 2, whereas BestBuy dropped from position 4 to position 6 . This is in contrast to the results obtained for the ranking based on survey data only, and is probably caused by the fact that while survey data is based on a subjective Likert scale, the perceptual data is collected with a very high precision by the eye tracking device.

\section{F. Comparison to Gaussian Preference}

In the final step of the analysis, the preference function of each of the criteria was changed to a Gaussian type, with $\mathrm{s}=3$ for the criteria $\mathrm{C} 1-\mathrm{C} 22, \mathrm{~s}=10$ for $\mathrm{E} 1$ and $\mathrm{E} 5, \mathrm{~s}=8$ for $\mathrm{E} 2$, $\mathrm{s}=5$ for $\mathrm{E} 3$ and $\mathrm{E} 6$ and $\mathrm{s}=50$ for $\mathrm{E} 4$. The resulting ranking is presented in Table VIII. It is very similar to the ranking obtained with the use of V-shape function with no indifference, except the shifts on positions 1-2 and 6-7. However, the ranking obtained with the Gaussian preference function is much more stable, which fact is presented in Table IX.

\section{Conclusions}

E-commerce is one of the most important sectors of online business. Considering the tough rivalry in the sector and continuous evolution of software, hardware and users' preferences, it is important to perform a systematic evaluation of e-commerce websites and their comparison to the ones owned by the competitors.

The prior MCDA methods were based on data collected from surveys or interviews. Some work has been done in the area of perceptual evaluation data usage, from eye tracking or EEG devices, in websites' evaluation. The authors' contribution in this paper was to extend the preexistent MCDA methods by the application of a combined survey and perceptual evaluation criteria set. In the proposed approach, a unique multistage construction of the model was realized. A new cluster of 6 perceptual evaluation criteria was added to the set of 22 eQual survey criteria.

An experiment was conducted to investigate the top 10 most popular e-commerce sites. Survey data from PEQUAL [17] was used to allow comparative analysis between results obtained by a Promethee II analysis based on survey-only criteria and combined criteria sets. Sensitivity and uncertainty analyses of the obtained rankings was performed. A study was performed on the influence of the preference function chosen on the ranking order and its stability. The GAIA analysis allowed to examine mutual dependencies between the survey and perceptual criteria.

The survey data allows researchers to learn about users' subjective opinions on the evaluated websites. The perceptual evaluation performed with the devices such as an eye tracker, on the other hand, provides palpable, measurable data. The extension of the survey data with the perceptual evaluation data from particular websites' parts, such as the home, product or payment page, allows to create rankings of quality of those websites with special emphasis on those parts. Nevertheless, survey data provides a more general view of the evaluated websites. Therefore, it is beneficial to combine the advantages provided by the both aforementioned kinds of data.

During the research, possible areas of improvement and future work directions were identified. It would be beneficial to increase the diversity of the perceptual criteria combined to the model. Also, more areas of the website could be evaluated with the use of eye tracking devices to provide more general metrics of the website quality. In the proposed approach, all perceptual criteria were grouped into a single cluster. Further research could be performed to introduce a more comprehensive structure of the perceptual evaluation criteria.

\section{REFERENCES}

[1] S. Kemp. (2017, jan) Digital in 2017 global overview. [Online]. Available: https://www.slideshare. netwearesocialsgdigital-in-2017-global-overview

[2] —. (2016, jan) Digital in 2016. [Online]. Available: https: //www.slideshare.net/wearesocialsg/digital-in-2016/537

[3] E. N. Europe. (2016, sep) Ecommerce in europe. [Online]. Available: https://ecommercenews.eu/ecommerce-per-country/ ecommerce-in-europe/

[4] R. Paul. (2015, jun) Just how big is the ecommerce market? youâĂŹll never guess! [Online]. Available: http://blog.lemonstand.com/ just-how-big-is-the-ecommerce-market-youll-never-guess/

[5] A. Strzelecki, M. Furmankiewicz, and P. Ziuziański, "The use of management dashboard in monitoring the efficiency of the internet advertising campaigns illustrated on the example of google analytics," Studia Ekonomiczne, vol. 296, pp. 136-150, 2016.

[6] J. Grigera, A. Garrido, J. I. Panach, D. Distante, and G. Rossi, "Assessing refactorings for usability in e-commerce applications," Empirical Software Engineering, vol. 21, no. 3, pp. 1224-1271, 2016. doi: 10.1007/s10664-015-9384-6. [Online]. Available: http: //dx.doi.org/10.1007/s10664-015-9384-6

[7] O. Sohaib and K. Kang, "Assessing web content accessibility of ecommerce websites for people with disabilities," 2016

[8] M. Olsson, Build a Profitable Online Business: The No-Nonsense Guide, 1st ed. Berkely, CA, USA: Apress, 2013. ISBN 1430263792, 9781430263791

[9] R. M. Kruger, H. Gelderblom, and W. Beukes, "The value of comparative usability and ux evaluation for e-commerce organisations," 2016.

[10] S. J. Barnes and R. Vidgen, "The equal approach to the assessment of e-commerce quality: A longitudinal study of," 2005.

[11] H. W. Webb and L. A. Webb, "Sitequal: an integrated measure of web site quality," Journal of Enterprise Information Management, vol. 17, no. 6, pp. 430-440, 2004.

[12] A. Parasuraman, V. A. Zeithaml, and A. Malhotra, "Es-qual a multipleitem scale for assessing electronic service quality," Journal of service research, vol. 7, no. 3, pp. 213-233, 2005.

[13] G. Kabir and M. Hasin, "Comparative analysis of topsis and fuzzy topsis for the evaluation of travel website service quality." International Journal for Quality Research, vol. 6, no. 3, 2012. 
TABLE VI

SENSITIVITY ANALYSIS - THE RANGES OF STABILITY FOR CRITERIA CLUSTERS FOR HOME, PRODUCT AND PAYMENT PAGES AND FOR THE AVERAGED SCENARIO

\begin{tabular}{|c|c|c|c|c|c|c|c|c|c|}
\hline \multirow{2}{*}{ Cluster of criteria } & \multirow{2}{*}{ Weight } & \multicolumn{2}{|l|}{ Home } & \multicolumn{2}{l|}{ Product } & \multicolumn{2}{l|}{ Payment } & \multicolumn{2}{l|}{ Average } \\
\cline { 3 - 10 } & & Min & Max & Min & Max & Min & Max & Min & Max \\
\hline Usability & $18.20 \%$ & $0.00 \%$ & $29.26 \%$ & $0.00 \%$ & $45.22 \%$ & $0.00 \%$ & $52.25 \%$ & $0.00 \%$ & $32.55 \%$ \\
\hline Information quality & $15.90 \%$ & $0.00 \%$ & $40.46 \%$ & $0.00 \%$ & $79.85 \%$ & $0.00 \%$ & $89.51 \%$ & $0.00 \%$ & $70.46 \%$ \\
\hline Service Interaction & $15.90 \%$ & $0.00 \%$ & $25.54 \%$ & $0.00 \%$ & $61.69 \%$ & $0.00 \%$ & $69.18 \%$ & $0.00 \%$ & $44.54 \%$ \\
\hline Perceptual & $50.00 \%$ & $42.15 \%$ & $100.00 \%$ & $23.42 \%$ & $82.30 \%$ & $18.93 \%$ & $74.69 \%$ & $33.56 \%$ & $78.35 \%$ \\
\hline
\end{tabular}

TABLE VII

RANKING OF WEBSITES BASED ON PROMETHEE II AND AVERAGE PERCEPTUAL EVALUATION DATA FROM HOME, PRODUCT AND PAYMENT PAGES, WITH INDIFFERENCE AREA

\begin{tabular}{|c|c|c|c|c|c|c|c|c|c|c|}
\hline Website & Apple & Staples & Amazon & eBay & Macy's & BestBuy & Rakuten & Target & Walmart & Alibaba \\
\hline$\phi$ & 0.0115 & 0.0049 & 0.0047 & 0.0019 & -0.0003 & -0.0017 & -0.0034 & -0.0035 & -0.0057 & -0.0085 \\
\hline Rank & 1 & 2 & 3 & 4 & 5 & 6 & 7 & 8 & 9 & 10 \\
\hline
\end{tabular}

TABLE VIII

RANKING OF WEBSITES BASED ON PROMETHEE II AND AVERAGE PERCEPTUAL EVALUATION DATA FROM HOME, PRODUCT AND PAYMENT PAGES, WITH GAUSSIAN PREFERENCE FUNCTION

\begin{tabular}{|c|c|c|c|c|c|c|c|c|c|c|}
\hline Website & Apple & Amazon & eBay & BestBuy & Staples & Macy's & Target & Walmart & Rakuten & Alibaba \\
\hline$\phi$ & 0.0232 & 0.0201 & 0.0134 & 0.0024 & 0.0017 & -0.0104 & -0.0105 & -0.0125 & -0.013 & -0.0145 \\
\hline Rank & 1 & 2 & 3 & 4 & 5 & 6 & 7 & 8 & 9 & 10 \\
\hline
\end{tabular}

TABLE IX

SENSITIVITY ANALYSIS FOR THE RANKING OBTAINED WITH GAUSSIAN PREFERENCE FUNCTION

\begin{tabular}{|c|c|c|}
\hline \multirow{2}{*}{ Cluster of criteria } & \multicolumn{2}{|c|}{ Weight } \\
\cline { 2 - 3 } & Min & Max \\
\hline Usability & $7.96 \%$ & $100.00 \%$ \\
\hline Information quality & $0.00 \%$ & $60.80 \%$ \\
\hline Service Interaction & $0.00 \%$ & $100.00 \%$ \\
\hline Perceptual & $0.00 \%$ & $64.92 \%$ \\
\hline
\end{tabular}

[14] J.-P. Brans and B. Mareschal, "Promethee methods," in Multiple criteria decision analysis: state of the art surveys. Springer, 2005, pp. 163-186.

[15] C.-C. Sun and G. T. Lin, "Using fuzzy topsis method for evaluating the competitive advantages of shopping websites," Expert Systems with Applications, vol. 36, no. 9, pp. 11764-11771, 2009.

[16] R. U. Bilsel, G. Büyüközkan, and D. Ruan, "A fuzzy preference-ranking model for a quality evaluation of hospital web sites," International Journal of Intelligent Systems, vol. 21, no. 11, pp. 1181-1197, 2006.

[17] J. Wątróbski, P. Ziemba, J. Jankowski, and W. Wolski, "Pequal-ecommerce websites quality evaluation methodology," in Computer Science and Information Systems (FedCSIS), 2016 Federated Conference on. IEEE, 2016, pp. 1317-1327.

[18] L. Chen and P. Pu, "Eye-tracking study of user behavior in recommender interfaces," in International Conference on User Modeling, Adaptation, and Personalization. Springer, 2010, pp. 375-380.

[19] K. Chang Lee, S. Wook Chae, and K. Chang Lee, "Exploring the effect of the human brand on consumers' decision quality in online shopping: An eye-tracking approach," Online Information Review, vol. 37, no. 1, pp. 83-100, 2013.

[20] L. Cowen, L. J. Ball, and J. Delin, "An eye movement analysis of web page usability," in People and Computers XVI-Memorable Yet Invisible. Springer, 2002, pp. 317-335.

[21] A. Bojko, Eye tracking the user experience. Rosenfeld Media, 2013.

[22] S. P. Roth, A. N. Tuch, E. D. Mekler, J. A. Bargas-Avila, and K. Opwis, "Location matters, especially for non-salient features-an eye-tracking study on the effects of web object placement on different types of websites," International journal of human-computer studies, vol. 71, no. 3, pp. 228-235, 2013.
[23] R. V. Menon, V. Sigurdsson, N. M. Larsen, A. Fagerstrøm, and G. R. Foxall, "Consumer attention to price in social commerce: Eye tracking patterns in retail clothing," Journal of Business Research, vol. 69, no. 11, pp. 5008-5013, 2016.

[24] J. Hernández-Méndez and F. Muñoz-Leiva, "What type of online advertising is most effective for etourism 2.0? an eye tracking study based on the characteristics of tourists," Computers in Human Behavior, vol. 50, pp. 618-625, 2015

[25] Q. Wang, S. Yang, M. Liu, Z. Cao, and Q. Ma, "An eye-tracking study of website complexity from cognitive load perspective," Decision support systems, vol. 62, pp. 1-10, 2014.

[26] S. Khodambashi, H. Gilstad, and Ø. Nytrø, "Usability evaluation of clinical guidelines on the web using eye-tracker." Studies in health technology and informatics, vol. 228, p. 95, 2016.

[27] P. Štrach and N. Slivkin, "Adaptation needed: Eye-tracking study of cross-cultural differences in perception of b2b websites," 2017.

[28] X. Yuan, M. Guo, F. Ren, and F. Peng, "Usability analysis of online bank login interface based on eye tracking experiment," Sensors \& Transducers, vol. 165, no. 2, p. 203, 2014.

[29] D. Albayrak and K. Cagiltay, "Analyzing turkish e-government websites by eye tracking," in Software Measurement and the 2013 Eighth International Conference on Software Process and Product Measurement (IWSM-MENSURA), 2013 Joint Conference of the 23rd International Workshop on. IEEE, 2013, pp. 225-230.

[30] B. Pan and L. Zhang, "An eyetracking study on online hotel decision making: The effects of images and umber of options," 2016.

[31] L. Hu, W. Zhang, and Q. Xu, "The determinants of online payment method choice: Insight from an eye-tracking study." in WHICEB, 2013, p. 80 .

[32] K. McSpadden, "You now have a shorter attention span than a goldfish," Time Online Magazine. Retrieved May, vol. 7, p. 2016, 2015.

[33] R. Weatherhead, "Say it quick, say it well-the attention span of a modern internet consumer," The Guardian Online, vol. 19, 2012.

[34] J. Nielsen, Usability engineering. Elsevier, 1994.

[35] I. Standardization, ISO 9241-11: Ergonomic Requirements for Office Work with Visual Display Terminals (VDTs): Part 11: Guidance on Usability, 1998. [Online]. Available: https://books.google.pl/books?id= TzXYZwEACAAJ

[36] I. Iso, "Iec 25010: 2011," Systems and software engineering-Systems and software Quality Requirements and Evaluation (SQuaRE)-System and software quality models, 2011. 
[37] A. Fernandez, E. Insfran, and S. Abrahão, "Usability evaluation methods for the web: A systematic mapping study," Information and Software Technology, vol. 53, no. 8, pp. 789-817, 2011.

[38] P. ZIEMBA and M. PIWOWARSKI, "Metody oceny jakości portali internetowych," 2010. [Online]. Available: http://www.pszw.edu.pl/images/publikacje/t027_pszw_2010_ziemba piwowarski_-_metody_oceny_jakosci_portali_internetowych.pdf

[39] F. D. Davis, "Perceived usefulness, perceived ease of use, and user acceptance of information technology," MIS quarterly, pp. 319-340, 1989.

[40] T. Ahn, S. Ryu, and I. Han, "The impact of the online and offline features on the user acceptance of internet shopping malls," Electronic Commerce Research and Applications, vol. 3, no. 4, pp. 405-420, 2005.

[41] H. Webb and L. Webb, "Business to consumer electronic commerce website quality: integrating information and service dimensions," AMCIS 2001 Proceedings, p. 111, 2001.

[42] A. Parasuraman, V. A. Zeithaml, and L. L. Berry, "Servqual: A multipleitem scale for measuring consumer perc," Journal of retailing, vol. 64, no. 1 , p. $12,1988$.

[43] J. Wątróbski, P. Ziemba, J. Jankowski, and W. Wolski, "Using pequal methodology in auction platforms evaluation process," in Conference on Advanced Information Technologies for Management. S Springer, 2016, pp. 222-241.

[44] T. M. La Porte, C. C. Demchak, and C. Friis, "Webbing governance: global trends across national-level public agencies," Communications of the $A C M$, vol. 44, no. 1, pp. 63-67, 2001.

[45] S. Elling, L. Lentz, and M. De Jong, "Website evaluation questionnaire: development of a research-based tool for evaluating informational websites," in International Conference on Electronic Government. Springer, 2007, pp. 293-304

[46] Z. Yang, S. Cai, Z. Zhou, and N. Zhou, "Development and validation of an instrument to measure user perceived service quality of information presenting web portals," Information \& Management, vol. 42, no. 4, pp. 575-589, 2005.

[47] G. M. Ping Zhang, "User expectations and rankings of quality factors in different web site domains," International Journal of Electronic Commerce, vol. 6, no. 2, pp. 9-33, 2001.

[48] M. Hassenzahl, "User experience (ux): towards an experiential perspective on product quality," in Proceedings of the 20th Conference on l'Interaction Homme-Machine. ACM, 2008, pp. 11-15.

[49] S. Kim and L. Stoel, "Dimensional hierarchy of retail website quality," Information \& Management, vol. 41, no. 5, pp. 619-633, 2004.
[50] W. Chmielarz and M. Zborowski, "Comparative analysis of electronic banking websites in selected banks in poland in 2014," in Computer Science and Information Systems (FedCSIS), 2015 Federated Conference on. IEEE, 2015, pp. 1499-1504.

[51] W. Chmielarz, "Evaluation of selected mobile applications stores from the userâĂŹs perspective," Online Journal of Applied Knowledge Management, vol. 3, no. 1, pp. 21-36, 2015.

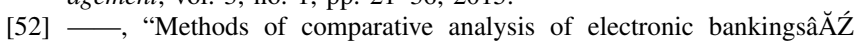
websites. case of poland," in 1-st CEE Symposium on Business Informatics, red. G. Chroust, G. Kotsis, V. Risak, N. Rozsenich, P. Zinterhof, Osterreichische Computer Gesellschaft, Vienna. Citeseer, 2009, pp. 73-84.

[53] A. Zenebe, L. Zhou, and A. F. Norcio, "User preferences discovery using fuzzy models," Fuzzy Sets and Systems, vol. 161, no. 23, pp. 3044-3063, 2010.

[54] L. Del Vasto-Terrientes, A. Valls, R. Slowinski, and P. Zielniewicz, "Electre-iii-h: An outranking-based decision aiding method for hierarchically structured criteria," Expert Systems with Applications, vol. 42, no. 11 , pp. 4910-4926, 2015.

[55] T. Kaya, "Multi-attribute evaluation of website quality in e-business using an integrated fuzzy ahptopsis methodology," International Journal of Computational Intelligence Systems, vol. 3, no. 3, pp. 301-314, 2010.

[56] J. Huang, X. Jiang, and Q. Tang, "An e-commerce performance assessment model: Its development and an initial test on e-commerce applications in the retail sector of china," Information \& Management, vol. 46, no. 2, pp. 100-108, 2009

[57] A. Guitouni, J.-M. Martel, P. Vincke, and P. North, "A framework to choose a discrete multicriterion aggregation procedure," Defence Research Establishment Valcatier (DREV), 1998.

[58] P. Ziemba, J. Wątróbski, J. Jankowski, and M. Piwowarski, "Research on the properties of the ahp in the environment of inaccurate expert evaluations," in Selected Issues in Experimental Economics. Springer, 2016, pp. 227-243.

[59] P. Ziemba and J. Wątróbski, "Selected issues of rank reversal problem in anp method," in Selected Issues in Experimental Economics. Springer, 2016, pp. 203-225.

[60] D. Bouyssou, E. Jacquet-Lagrèze, P. Perny, R. Slowiński, D. Vanderpooten, and P. Vincke, Aiding decisions with multiple criteria: essays in honor of Bernard Roy. Springer Science \& Business Media, 2012, vol. 44.

[61] B. Roy, Multicriteria methodology for decision aiding. Springer Science \& Business Media, 2013, vol. 12. 
APPEndiX: PERFormance tABle FOR Promethee II BASED ON MEAN VALUES OF CRITERION EVALUATIONS

\begin{tabular}{|c|c|c|c|c|c|c|c|c|c|c|c|}
\hline \multirow{2}{*}{ Group of criteria } & \multirow{2}{*}{ Criterion } & \multicolumn{10}{|l|}{ Website } \\
\hline & & Alibaba & Amazon & Apple & BestBuy & eBay & MacyâĂŹzs & Rakuten & Staples & Target & Walmart \\
\hline \multirow{4}{*}{ Usability } & $\mathrm{C} 1$ & 4.902 & 5.610 & 5.683 & 5.000 & 6.024 & 5.049 & 4.976 & 4.927 & 4.854 & 5.049 \\
\hline & $\mathrm{C} 2$ & 4.951 & 5.707 & 5.415 & 4.878 & 5.951 & 4.976 & 5.098 & 4.927 & 4.756 & 5.220 \\
\hline & $\mathrm{C} 3$ & 5.000 & 5.317 & 5.610 & 5.000 & 5.610 & 4.854 & 4.805 & 4.829 & 4.683 & 4.829 \\
\hline & $\mathrm{C} 4$ & 4.829 & 5.390 & 5.585 & 4.878 & 5.634 & 5.049 & 4.854 & 4.659 & 4.854 & 5.244 \\
\hline \multirow{4}{*}{ Site design } & $\mathrm{C} 5$ & 4.829 & 5.024 & 5.976 & 4.341 & 4.683 & 4.707 & 4.268 & 4.512 & 4.220 & 4.927 \\
\hline & C6 & 5.098 & 5.488 & 6.024 & 4.561 & 5.341 & 5.049 & 4.707 & 4.927 & 4.707 & 4.805 \\
\hline & $\mathrm{C} 7$ & 4.829 & 5.366 & 5.829 & 4.537 & 4.878 & 4.756 & 4.439 & 4.732 & 4.415 & 4.805 \\
\hline & $\mathrm{C} 8$ & 4.634 & 5.146 & 5.415 & 4.049 & 4.512 & 4.585 & 4.024 & 4.220 & 3.683 & 4.268 \\
\hline \multirow{7}{*}{ Information quality } & C9 & 5.000 & 5.537 & 5.049 & 5.073 & 5.634 & 4.780 & 4.805 & 4.780 & 4.756 & 4.537 \\
\hline & $\mathrm{C} 10$ & 4.902 & 5.537 & 5.902 & 5.098 & 5.683 & 4.902 & 5.024 & 4.805 & 4.902 & 4.805 \\
\hline & $\mathrm{C} 11$ & 5.585 & 5.268 & 5.488 & 5.122 & 5.415 & 5.512 & 5.488 & 5.146 & 5.561 & 5.317 \\
\hline & $\mathrm{C} 12$ & 4.951 & 5.463 & 5.341 & 5.268 & 5.537 & 4.902 & 4.732 & 4.854 & 5.049 & 4.610 \\
\hline & $\mathrm{C} 13$ & 4.732 & 5.537 & 5.561 & 5.244 & 5.512 & 4.878 & 4.756 & 4.707 & 4.902 & 4.976 \\
\hline & $\mathrm{C} 14$ & 4.854 & 5.488 & 5.171 & 5.098 & 5.220 & 4.634 & 4.659 & 4.854 & 5.024 & 4.488 \\
\hline & $\mathrm{C} 15$ & 4.927 & 5.390 & 5.293 & 4.854 & 5.488 & 4.732 & 4.512 & 4.829 & 4.756 & 4.951 \\
\hline \multirow{4}{*}{ Trust } & $\mathrm{C} 16$ & 4.927 & 5.829 & 5.927 & 4.244 & 5.878 & 4.512 & 4.415 & 4.488 & 4.195 & 4.927 \\
\hline & $\mathrm{C} 17$ & 4.732 & 5.805 & 6.000 & 4.537 & 5.659 & 4.512 & 4.293 & 4.927 & 4.317 & 4.951 \\
\hline & $\mathrm{C} 18$ & 4.732 & 5.610 & 5.805 & 4.707 & 5.561 & 4.659 & 4.390 & 4.780 & 4.220 & 4.902 \\
\hline & $\mathrm{C} 22$ & 4.683 & 5.610 & 6.171 & 4.634 & 5.268 & 4.756 & 4.220 & 4.683 & 4.220 & 4.902 \\
\hline \multirow{3}{*}{ Empathy } & $\mathrm{C} 19$ & 3.951 & 4.927 & 4.878 & 3.537 & 4.049 & 3.976 & 3.659 & 3.756 & 3.366 & 3.951 \\
\hline & $\mathrm{C} 20$ & 3.878 & 4.683 & 4.293 & 3.366 & 3.488 & 3.439 & 3.463 & 3.610 & 3.146 & 3.756 \\
\hline & $\mathrm{C} 21$ & 4.780 & 5.268 & 5.561 & 4.829 & 5.293 & 4.610 & 4.268 & 4.390 & 4.610 & 4.732 \\
\hline \multirow{6}{*}{ Home pages } & E1 & 10 & 15 & 14 & 18 & 16 & 10 & 12 & 16 & 17 & 10 \\
\hline & E2 & 5.210 & 5.00 & 4.64 & 1.85 & 3.27 & 4.41 & 3.35 & 3.91 & 3.32 & 3.65 \\
\hline & E3 & 0.390 & 0.53 & 1.06 & 0.98 & 0.60 & 0.41 & 0.62 & 0.65 & 0.81 & 0.43 \\
\hline & $\mathrm{E} 4$ & 3.870 & 5.27 & 10.57 & 9.83 & 6.04 & 4.06 & 6.24 & 6.45 & 8.11 & 4.27 \\
\hline & E5 & 6 & 13 & 9 & 18 & 13 & 6 & 10 & 11 & 16 & 6 \\
\hline & E6 & 1.800 & 2.50 & 5.10 & 3.40 & 2.50 & 3.80 & 3.10 & 2.50 & 4.90 & 2.80 \\
\hline \multirow{6}{*}{ Product pages } & E1 & 20 & 20 & 20 & 20 & 20 & 20 & 18 & 18 & 19 & 20 \\
\hline & E2 & 1.990 & 2.04 & 2.73 & 1.47 & 1.67 & 1.39 & 1.60 & 1.25 & 1.94 & 1.91 \\
\hline & E3 & 2.030 & 2.70 & 3.22 & 2.83 & 1.84 & 2.55 & 2.31 & 3.14 & 1.85 & 0.80 \\
\hline & $\mathrm{E} 4$ & 20.280 & 21.70 & 32.25 & 28.27 & 18.41 & 25.49 & 23.15 & 31.45 & 18.48 & 7.98 \\
\hline & E5 & 17 & 19 & 15 & 18 & 18 & 19 & 18 & 18 & 16 & 16 \\
\hline & E6 & 2.300 & 5.50 & 3.50 & 4.60 & 5.40 & 5.10 & 5.50 & 5.30 & 6.50 & 2.90 \\
\hline \multirow{6}{*}{ Payment pages } & E1 & 20 & 20 & 19 & 20 & 18 & 17 & 17 & 20 & 16 & 20 \\
\hline & E2 & 2.350 & 0.32 & 1.96 & 2.93 & 1.15 & 2.85 & 4.54 & 0.32 & 3.22 & 2.88 \\
\hline & E3 & 0.990 & 3.67 & 2.57 & 2.93 & 3.86 & 0.90 & 2.01 & 4.97 & 0.97 & 1.83 \\
\hline & $\mathrm{E} 4$ & 9.890 & 36.72 & 25.69 & 29.26 & 38.61 & 8.96 & 20.10 & 49.70 & 9.70 & 18.30 \\
\hline & E5 & 17 & 20 & 18 & 18 & 18 & 14 & 16 & 20 & 15 & 18 \\
\hline & E6 & 4.20 & 4.30 & 6.30 & 4.30 & 4.00 & 6.40 & 4.50 & 3.90 & 4.20 & 4.80 \\
\hline
\end{tabular}

